\title{
Receptive field size-dependent attention effects in simultaneously presented stimulus displays
}

Citation for published version (APA):

Bles, M., Schwarzbach, J. V., de Weerd, P. H. M., Goebel, R. W., \& Schmitt, B. M. (2006). Receptive field size-dependent attention effects in simultaneously presented stimulus displays. Neuroimage, 30, 506-511. https://doi.org/10.1016/j.neuroimage.2005.09.042

Document status and date:

Published: 01/01/2006

DOI:

10.1016/j.neuroimage.2005.09.042

Document Version:

Publisher's PDF, also known as Version of record

Document license:

Taverne

Please check the document version of this publication:

- A submitted manuscript is the version of the article upon submission and before peer-review. There can be important differences between the submitted version and the official published version of record.

People interested in the research are advised to contact the author for the final version of the publication, or visit the DOI to the publisher's website.

- The final author version and the galley proof are versions of the publication after peer review.

- The final published version features the final layout of the paper including the volume, issue and page numbers.

Link to publication

\footnotetext{
General rights rights.

- You may freely distribute the URL identifying the publication in the public portal. please follow below link for the End User Agreement:

www.umlib.nl/taverne-license

Take down policy

If you believe that this document breaches copyright please contact us at:

repository@maastrichtuniversity.nl

providing details and we will investigate your claim.
}

Copyright and moral rights for the publications made accessible in the public portal are retained by the authors and/or other copyright owners and it is a condition of accessing publications that users recognise and abide by the legal requirements associated with these

- Users may download and print one copy of any publication from the public portal for the purpose of private study or research.

- You may not further distribute the material or use it for any profit-making activity or commercial gain

If the publication is distributed under the terms of Article $25 \mathrm{fa}$ of the Dutch Copyright Act, indicated by the "Taverne" license above, 


\title{
NeuroImage
}

\section{Receptive field size-dependent attention effects in simultaneously presented stimulus displays}

\author{
Mart Bles, ${ }^{\mathrm{a}, *}$ Jens Schwarzbach, ${ }^{\mathrm{a}, \mathrm{b}}$ Peter De Weerd, ${ }^{\mathrm{a}}$ \\ Rainer Goebel, ${ }^{\mathrm{a}}$ and Bernadette M. Jansma ${ }^{\mathrm{a}}$ \\ a Maastricht University, Faculty of Psychology, Department of Cognitive Neuroscience, Maastricht, The Netherlands \\ ${ }^{\mathrm{b}}$ FC Donders Centre for Cognitive Neuroimaging, Nijmegen, The Netherlands
}

Received 28 April 2005; revised 15 September 2005; accepted 23 September 2005

Available online 26 October 2005

\begin{abstract}
Neurophysiological studies in monkeys show that multiple stimuli presented within the receptive field of a neuron are not processed independently but rather act in a mutually suppressive way. Recently, such suppressive interactions have also been reported in human neuroimaging studies. This is seen as evidence that stimuli compete for neural representation. According to the 'biased competition' approach, attention can bias this competition in favor of the attended stimulus, relieving it of the suppressive influences of the distracters. In this paper, we report data that support these findings. Specifically, the effect of attention on stimuli with different spatial separations was investigated more thoroughly. The biased competition approach would predict that, for a given spatial separation and eccentricity, the difference between attended and unattended displays depends on the receptive field size of an area. In a blocked fMRI experiment, participants viewed four simultaneously presented, colorful pictures under different attention conditions (attended and unattended). Stimuli were separated either $2^{\circ}$, $4^{\circ}$ or $7^{\circ}$. In line with previous experiments, we found that the effect of attention correlated with the estimated receptive field size of an area. In areas V1, V2 and VP, where estimated receptive field sizes are small, no significant attention effects were found in any of the spatial separation conditions. In V4, there was a significant difference between attended and unattended conditions for the $2^{\circ}$ and $4^{\circ}$ spatial separations, but not for $7^{\circ}$. Finally in area TEO, significant differences between attended and unattended conditions were observed for all spatial separations.
\end{abstract} (C) 2005 Elsevier Inc. All rights reserved.

\section{Introduction}

Only a few of the objects presented to us in a typical visual scene are behaviorally relevant. Our brain selects these stimuli for further processing and filters out other, unwanted information through a process referred to as attention (Broadbent, 1958; Treisman, 1969).

\footnotetext{
* Corresponding author. Universiteit Maastricht, Faculteit der Psychologie, Capacititeitsgroep Neurocognitie, PO Box 616, 6200 MD Maastricht, The Netherlands. Fax: +31 433884125.

E-mail address: M.Bles@psychology.unimaas.nl (M. Bles).

Available online on ScienceDirect (www.sciencedirect.com).
}

The present research project aimed at further investigating the mechanisms that underlie stimulus selection. More specifically, we tested hypotheses derived from a 'biased competition' account of visual attention (for an overview, see Desimone and Duncan, 1995; Kastner and Ungerleider, 2001b), which has been based primarily on neurophysiological studies in animals (e.g., Chelazzi et al., 1998; Luck et al., 1997; Moran and Desimone, 1985; Reynolds et al., 1999), but which has recently received support from human neuroimaging studies (Kastner et al., 1998, 1999, 2001; Pinsk et al., 1999).

Evidence from single-cell recordings in extrastriate cortex indicates that whenever multiple stimuli are presented within the receptive field (RF) of a neuron in the absence of attention, these stimuli compete for control over that neuron's firing rate. When, for example, an effective and an ineffective stimulus are presented together within the RF of a macaque V2 or V4 neuron, the cell responds with a firing rate that is a weighted average of the firing rates evoked by the single stimuli (Chelazzi et al., 1998, 2001; Luck et al., 1997; Miller et al., 1993; Moran and Desimone, 1985; Recanzone et al., 1997; Reynolds et al., 1999). Thus, instead of being processed independently, multiple stimuli within the RF of a neuron can be seen as mutually suppressing each other's representation and competing for neural resources.

The competition between stimuli can be biased by attending one of them. When one of the stimuli is attended, the neuron's firing rate reflects the presence of the attended stimulus. If the effective stimulus is attended, the neuron's firing rate increases to a level that is approximately the same as when the effective stimulus is presented alone. Likewise, if the ineffective stimulus is attended, the firing rate decreases to the level that can be observed when the ineffective stimulus is presented alone (Chelazzi et al., 1998, 2001; Luck et al., 1997; Moran and Desimone, 1985; Reynolds et al., 1999). Clearly, attention does not merely enhance responses to attended stimuli. Rather, in the case of multiple stimuli, attention filters out the influence of surrounding stimuli. The processing of the attended stimulus gains precedence over that of others and the neuron's firing rate will reflect the presence of the attended stimulus and not of the distracters. 
Similarly, Kastner et al. (1998, 1999, 2001) found evidence for competitive interactions between stimuli in the human visual cortex. In an fMRI experiment, participants saw displays of four complex, colorful, visual stimuli. These stimuli were either presented simultaneously or sequentially. In the simultaneous condition stimuli compete for neural representation since visual areas have to process the information of several stimuli at the same time. In the sequential condition, there is only one stimulus presented at a time, preventing competition between stimuli. The BOLD response in subjects' visual areas V2/VP, V4 and TEO was decreased when stimuli were presented simultaneously as compared to the signal obtained when stimuli were presented simultaneously. The authors interpreted these findings as evidence that during simultaneous stimulation the neural representations of the different stimuli interact in a suppressive way and that no such competition takes place in sequential stimulation (Kastner et al., 1998, 2001). Moreover, suppression effects were not observed when subjects attended one of the stimuli, suggesting that attention biased the competition in favor of the attended item, relieving it from the suppressive effects of the surrounding stimuli (Kastner et al., 1998, 1999).

As visual areas are located further up the cortical visual processing stream, their average RF size increases. As a consequence, on average more stimuli will be present within the RFs of higher order areas compared to lower order areas, given an identical display. This leads to the prediction that stronger competitive interactions between stimuli should be observed in higher order areas, since neurons in these areas have larger RFs (see Fig. 1). Indeed, Kastner et al. (1998, 1999, 2001) observed that the competitive interactions were not of the same magnitude in all visual areas. No competition effects were found in V1, where RF sizes are so small that no stimuli will simultaneously fall within the same RF. However, competitive interactions were observed in $\mathrm{V} 2 / \mathrm{VP}$ and this effect was even more pronounced in more anterior areas like V4 and TEO. In line with the biased competition theory, this suggests that the magnitude of the competitive interaction effect is scaled with RF size of an area.

Further evidence that competitive interactions between stimuli are dependent on RF size was found in a follow-up study (Kastner et al., 2001; Pinsk et al., 1999). In this study, the spatial separation between the stimuli in the display was systematically varied. By placing stimuli further apart, less of them will fall within the same RF (see Fig. 1) and therefore weaker competitive interactions should be observed. Indeed, the magnitude of the suppressive interactions could be decreased within areas by increasing stimulus separation. The degree to which display spacing affected suppressive interactions decreased as areas were placed higher up the visual stream, where RF sizes increase.

A potential drawback of the method described above is that by comparing the activation in the sequential condition with that in the simultaneous condition, a higher amount of transient stimulus onsets is present in sequential trials as opposed to simultaneous trials. Because the magnitude of the hemodynamic response is dependent on the number of transient stimulus onsets (Fox and Raichle, 1985; Price et al., 1996; Rees et al., 1997; Schneider et al., 1994), the higher BOLD signal change in sequential conditions might be explained by the higher number of stimulus onsets, rather than a reduced amount of suppression (Kastner et al., 1998, 2001). There are, however, several arguments why this seems unlikely. First of all, in a control condition in which the stimulation rate was kept constant, distracter stimuli placed in the lower visual field

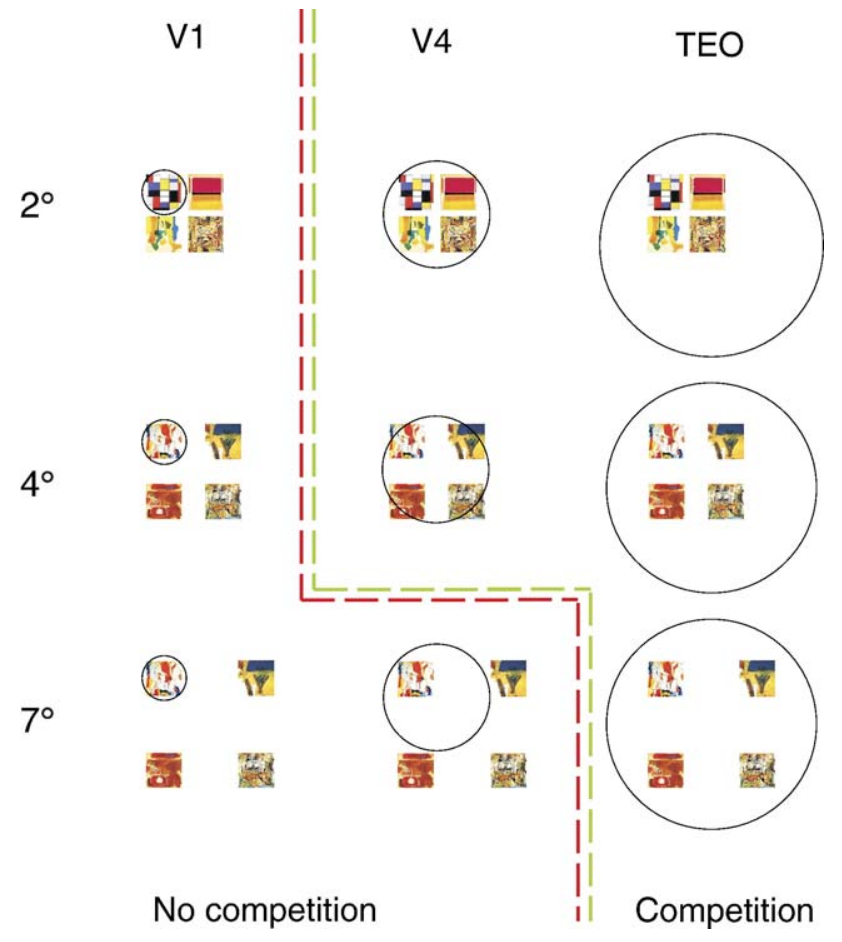

Fig. 1. Illustration of hypotheses. Displayed are 3 schematic receptive fields of different sizes (V1, V4 and TEO, respectively), with stimuli with 3 different spatial separations $\left(2^{\circ}, 4^{\circ}\right.$ and $\left.7^{\circ}\right)$ superimposed. Competition between stimuli should only occur when multiple stimuli fall within the same RF, i.e., in the upper row only in the 2 rightmost RFs, and in the lower row only in the rightmost RF. Regions of interest were the visual areas V1 $\left(<1^{\circ}\right), \mathrm{V} 2\left(1-2^{\circ}\right), \mathrm{VP}\left(2^{\circ}\right), \mathrm{V} 4\left(4^{\circ}\right)$ and TEO $\left(7^{\circ}\right)$ (estimated RF size at this eccentricity between brackets).

were shown to suppress the response to a stimulus presented alone in the upper visual field, indicating that it was not presentation rate, but distracter presence which controlled the amount of suppression (for more details, see Kastner et al., 2001). Furthermore, if the higher number of transient onsets would be the cause of the increased BOLD signal change in the sequential condition, then this effect should be relatively equal over visual areas and spatial separations (Rees et al., 1997; Schneider et al., 1994). Instead, Kastner et al. $(1998,2001)$ found that the size of the suppression effect was dependent on RF size of an area and the amount of separation between stimuli. Similarly, if the amount of transient onsets explained the difference between the simultaneous and the sequential condition, a similar attention effect should have been present in the simultaneous and the sequential conditions (Rees et al., 1997). Instead, when comparing simultaneously presented with sequentially presented items, attention effects in V4 were larger in the simultaneous condition (Kastner et al., 1998).

So far, the studies by Kastner et al. are the only ones which demonstrate biased competition in humans. In these studies, attention effects for simultaneously presented stimuli were only investigated in V1 and V4 and only for one spatial separation (Kastner et al., 1998). The role of spatial separation was only investigated by looking at the difference between simultaneous and sequential conditions in the absence of attention (Kastner et al., 2001). Our goal was to replicate and extend these findings. We chose a design which on the one hand investigates the role of attention in displays of various spatial separations more thoroughly, while on the other hand removing the need for the 
'sequential' condition. In the present study, the factors attention, spatial separation and visual area were completely crossed, which enabled us to gain a more comprehensive look on the interactions between RF size, competition and the effects of selective attention. In a modified version of the block design used by Kastner et al. (1998, 1999, 2001) and Pinsk et al. (1999), participants viewed four abstract, colorful stimuli that were always simultaneously presented in the upper right quadrant of the visual field. We looked at the difference between attended and unattended conditions in several visual areas (V1, V2, VP, V4v and TEO) and for three different spatial separations $\left(2^{\circ}, 4^{\circ}\right.$ and $\left.7^{\circ}\right)$.

The difference in BOLD signal change between attended and unattended conditions was expected to be scaled with RF size and stimulus separation. We predicted the presence of this attention effect in an area on the basis of estimates of RF sizes for that area; the smallest spatial separation that leads to attention effects should match the size of the RF of that area at that eccentricity. Note that in the present study, stimuli were presented closer to the fovea (closest picture centered at $2.5^{\circ}$ eccentricity from the fixation point) than in the Kastner et al. $(1998,2001)$ studies (display of four pictures centered at $\sim 5.5^{\circ}$ eccentricity).

Furthermore, we chose to present the attended stimulus always at the same position. In a display with a constant center, increases in display size entail that the target picture (at the lower left location) is displayed at different eccentricities and therefore undergoes different cortical magnifications. This would give the target picture different weights in its competition with the other stimuli. The effects of cortical magnification declines quickly with increasing eccentricity, and to limit the effects of magnification we chose for an expansion of the display towards greater eccentricities, keeping the stimulus closest to fixation (target) at a constant eccentricity. A drawback of this approach is that the increased eccentricity of display center associated with increased display size causes RF size to increase, antagonizing the predicted effects of display size on attention effects, thus causing an underestimation of the attention effects.

Based on monkey electrophysiology (Boussaoud et al., 1991; Gattass et al., 1981; Gattass et al., 1988), and fMRI estimates of RF sizes in humans (Smith et al., 2001), RF size estimates at this eccentricity are smaller than $1^{\circ}$ for $\mathrm{V} 1,1-2^{\circ}$ for $\mathrm{V} 2, \sim 2^{\circ}$ for $\mathrm{VP}$, $3-4^{\circ}$ for $\mathrm{V} 4 \mathrm{v}$ and $6-7^{\circ}$ for TEO. This means that for the $2^{\circ}$ spatial separation condition in this study, the earliest area where to expect attention effects is VP, for the $4^{\circ}$ condition it is V4 and for the $7^{\circ}$ condition it is TEO.

\section{Methods}

\section{Subjects}

Eight healthy volunteers ( 2 male, age 20-26 years) were paid for participation in this study, which was approved by an ethical committee. After explanation of the procedures, participants signed an informed consent form. None of the subjects had any prior psychiatric or neurological history, and all were in good health and had normal or corrected to normal visual acuity.

\section{Visual task}

Display conditions were identical for attended and unattended conditions. When no pictures were displayed, there was a blank screen with a fixation cross. Trials consisted of displays of four pictures, which were randomly composed from a database of 135 complex, colorful pictures, each $1^{\circ} \times 1^{\circ}$ in size. The displays were presented in the upper right quadrant of the visual field. During periods where pictures were present on the screen, an ' $\mathrm{L}$ ' or a ' $\mathrm{T}$ ' replaced the fixation cross. Participants performed one of two tasks. In the 'unattended' condition, subjects had to fixate on the center of the screen and had to count how often the fixation cross changed into a certain target letter, ignoring the pictures in the upper right quadrant. In the 'attend' condition, subjects were instructed to fixate the center of the screen but to covertly attend the picture that was presented closest to the fixation point and to count the occurrence of a target picture at that location. In an eventrelated potential study involving the identical parameters as the current study, no differences in eye movements were found across degree conditions.

Target frequency randomly varied between 1 and 4 targets per block for both tasks. Picture displays covered an area of either $2^{\circ} \times$ $2^{\circ}, 4^{\circ} \times 4^{\circ}$ or $7^{\circ} \times 7^{\circ}$ of the visual field. The picture closest to the fixation point was always centered at $2.5^{\circ}$ from fixation point.

The order of the six blocks was randomized for each participant. Each block lasted $12 \mathrm{~s}$ and was preceded and followed by a blank screen for $16 \mathrm{~s}$ (see Fig. 2). In between blocks, participants were asked to indicate their answer with a button press ( $3 \mathrm{~s}$ timeout) and received instructions for the next block $(6 \mathrm{~s})$. Stimuli had a duration of $250 \mathrm{~ms}$ and were presented at a rate of $1 \mathrm{~Hz}$.

Each participant performed three runs, lasting about $7 \mathrm{~min}$ each, followed by an anatomical scan and the retinotopic mapping runs (see below for scan parameters).

\section{Data acquisition}

Images were acquired on a 3-T Siemens Trio Scanner (Siemens Medical Systems, Erlangen, Germany) using a standard head coil. Twenty-nine oblique axial slices (in-plane resolution: $3.5 \times 3.5$ $\mathrm{mm}$; slice thickness: $4.5 \mathrm{~mm}$; interslice distance $0 \mathrm{~mm}$ ) covering the entire cortical volume were acquired using an echo planar imaging sequence $(\mathrm{TR}=2000 \mathrm{~ms}, \mathrm{TE}=29 \mathrm{~ms}$, matrix size: $64 \times$ 64). There were 175 volumes per run, the first 4 of which were skipped due to the T1 saturation effect. Functional slices of each run were aligned to a high-resolution anatomical data set acquired after the functional runs (Magnetization-Prepared Rapid Acquisition Gradient Echo (MPRAGE); TR $=2300 \mathrm{~ms}$, TE $=3.93 \mathrm{~ms}$, 192 slices).

The participants were placed comfortably in the scanner and their head was fixated with foam pads. Mounted on the head coil was a mirror through which they could see the stimuli projected on a screen placed outside the scanner. Stimulus presentation was synchronized with MR data acquisition by triggering the stimulus program with the first MR pulse.

\section{Retinotopic mapping}

For each subject retinotopic maps were created (Goebel et al., 2003; Sereno et al., 1995). Polar maps were acquired using a rotating, red-green blocked wedge of $33.75^{\circ}$ polar angle covering eccentricities from $1^{\circ}$ to $17^{\circ}$ visual angle. Wedges were filled with a checkerboard pattern of red and green squares that reversed polarity eight times per second and did a full rotation within $64 \mathrm{~s}$. Thus, each pixel in a circular field of view was activated every $64 \mathrm{~s}$ for a duration of $6 \mathrm{~s}$. A functional run took $552 \mathrm{~s}$, i.e., 8 cycles of 


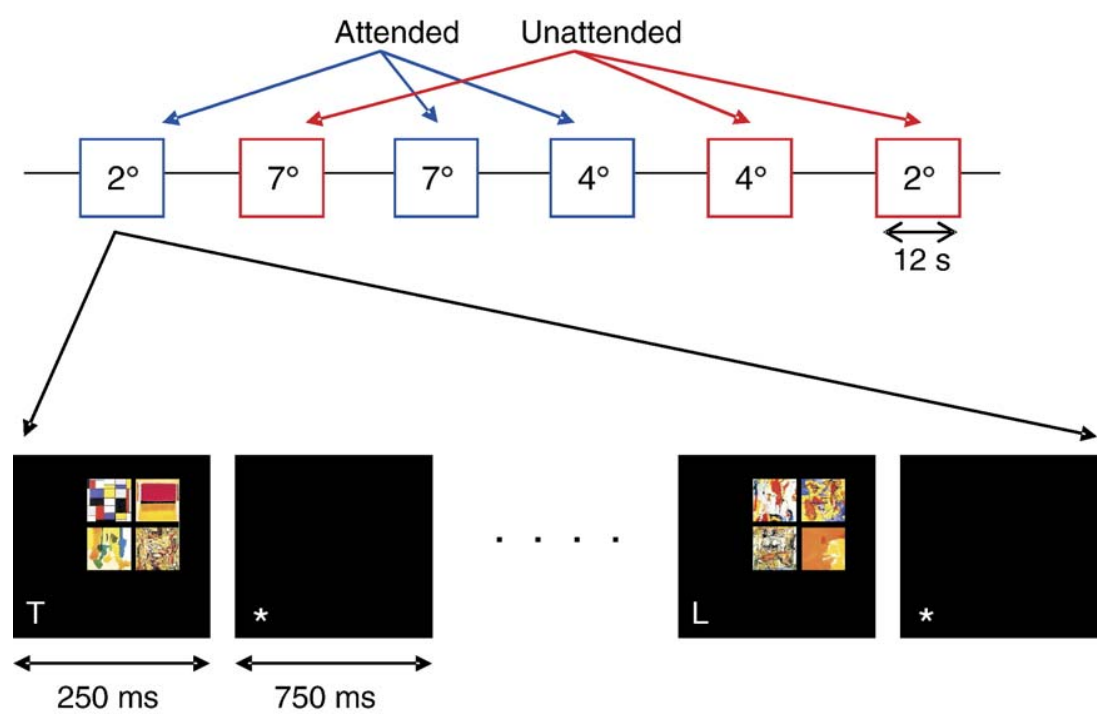

Fig. 2. Experimental design. Each block lasted a total of $12 \mathrm{~s}$ and contained 12 picture presentations. Pictures were displayed on screen for $250 \mathrm{~ms}$, followed by a blank screen with a fixation point for a duration of $750 \mathrm{~ms}$. Blocks were separated by an 18-s blank screen, a 3-s answer period (button-press), a 6-s instruction for the new block (target indication and location) and another 18-s blank screen.

rotating wedges plus $20 \mathrm{~s}$ lead in and lead out time. Scanning parameters: $\mathrm{TR}=2000 \mathrm{~ms}, \mathrm{TE}=30 \mathrm{~ms}, 30$ slices, voxel size $3.5 \times$ $3.5 \mathrm{~mm}$, matrix size $64 \times 64$. Ventral visual areas V1, V2, VP and V4 were defined for each subject. Area TEO could not be reliably located for most subjects by this method, but was defined as the area anterior to V4 that was activated reliably by the stimuli across subjects, and was located at comparable Talairach coordinates as in the Kastner et al. (1998) study (see Fig. 3). Mean Talairach coordinates of each defined area are displayed in Table 1. ROIs were defined as those voxels of the mapped visual areas that showed significant activation in a contrast of all unattended conditions versus baseline (fixation), assuming that these activated areas include neurons with RF sensitive to the stimulated location. We thereby restricted data analysis to those voxels of the visual cortex in which the processing of our stimuli took place. The ROIs within each area were identical for each spatial separation condition.

\section{Analysis}

Functional and anatomical images were analyzed with the BrainVoyager 2000 and BrainVoyager QX software packages (Brain Innovation, Maastricht, The Netherlands). Functional runs were corrected for slice scan time (using sinc interpolation) and for $3 \mathrm{D}$ head motion by using rigid body transformations. Linear trends and low-frequency nonlinear drifts $(<3 \mathrm{~Hz})$ were removed from the data. Functional data were then aligned to the anatomical scans and transformed into Talairach space. After definition of ROIs per subject (see "retinotopic mapping"), GLM beta weights were obtained per participant for all ROIs for each run, as an estimation of the contribution to the overall explained variance in the signal in the target area in a specific condition. These were then analyzed using a general linear model (repeated measures) with separate factors for spatial separation $\left(3 ; 2^{\circ}, 4^{\circ}\right.$ and $\left.7^{\circ}\right)$, attention (2; attended and unattended) and visual area (5; V1, V2, VP, V4 and TEO). Thereafter, paired samples $t$ tests were performed with both attention conditions as the paired variables, separately for each ROI and spatial separation. This enabled us to test the prediction that the smallest spatial separation that led to attention effects in an area was of the same magnitude as the estimated RF size for that area.

\section{Results}

The presentation of the stimuli activated areas V1, V2, VP, V4 and TEO across subjects. Statistics are summarized in Table 2. Fig. 4 shows grouped beta weight differences between attended and unattended conditions for each area and for each spatial separation. The difference between attended and unattended conditions was

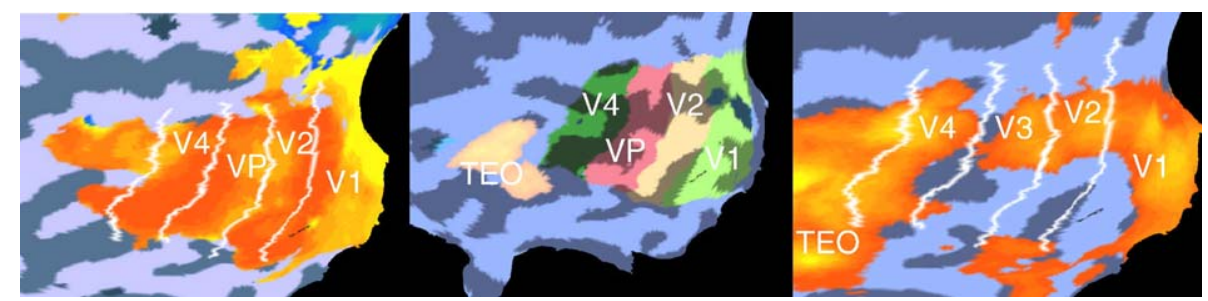

Fig. 3. Regions of interest definition for one representative subject. The left graph shows the results of the polar mapping runs. The middle graph shows a flatmap of the visual areas defined by the polar mapping, including a projection of the activated part of area TEO. Shown in the right graph is the activation in 'unattended' conditions compared with baseline (fixation) to demonstrate which part of each visual area was taken as ROI across spatial separation conditions for this subject. 
Table 1

Mean Talairach coordinates of visual areas of interest $(\mathrm{mm} \pm \mathrm{SD})$

\begin{tabular}{lllr}
\hline Area & \multicolumn{1}{l}{$y$} & \multicolumn{1}{l}{$z$} \\
\hline V1 & $-4 \pm 3$ & $-81 \pm 5$ & $-9 \pm 6$ \\
V2 & $-8 \pm 2$ & $-77 \pm 5$ & $-15 \pm 5$ \\
VP & $-16 \pm 2$ & $-75 \pm 5$ & $-16 \pm 4$ \\
V4 & $-22 \pm 2$ & $-72 \pm 6$ & $-15 \pm 5$ \\
TEO & $-26 \pm 2$ & $-53 \pm 9$ & $-12 \pm 4$ \\
\hline
\end{tabular}

significant $(F(1,22)=13.03, P<0.01)$, with attended displays leading to higher beta weights, indicating that the BOLD signal changes in this condition were higher than in unattended conditions. As can bee seen in Fig. 4, this difference increased as areas were located higher up the visual processing stream, which was reflected in a significant Attention $\times$ Area interaction $(F(4,88)=48.00, P<0.001)$. Furthermore, there was a significant main effect of spatial separation $(F(2,44)=3.76, P<0.05)$; overall activation was highest for the $4^{\circ}$ conditions, followed by the $7^{\circ}$ and then the $2^{\circ}$ conditions. We also observed a main effect of area $(F(4,88)=59.95, P<0.001)$; higher order areas tended to show higher beta weights than lower order areas. Finally, we observed a significant interaction between spatial separation and area $(F(8,176)=5.01, P<0.005)$.

Due to the main effect of area and the interactions of this factor with attention and spatial separation, we decided to look at each area separately by means of paired samples $t$ tests. These tests revealed that the difference in beta weights between attended and unattended conditions did depend on RF size of an area. In area $\mathrm{V} 4$, this difference was significant for both $2^{\circ}$ and $4^{\circ}$ displays, (paired samples $t$ test, $t(22)>2.074, P<0.005$ ), but not for $7^{\circ}$ displays. Furthermore, GLM within-subjects difference contrasts show that the $7^{\circ}$ condition marginally differs from the $2^{\circ}$ and $4^{\circ}$ conditions: $F(1,22)=4.04, P=0.057$. In area TEO, all spatial separations led to a significant difference between attended and unattended conditions $(t(22)>2.074, P<0.05)$. In none of the other areas, the difference between attended and unattended conditions significantly deviated from zero.

\section{Discussion}

In the current study, we aimed to support earlier findings by Kastner et al. (1998, 1999, 2001), who found that BOLD signal change in the human brain during visual processing of pictures is

Table 2

Statistics overview

\begin{tabular}{lrll}
\hline Factor & $F$ value & $d f$ & $P$ value \\
\hline Attention & 13.03 & 1,22 & $0.002^{* *}$ \\
Spatial separation & 3.76 & 2,44 & $0.031^{*}$ \\
Area & 59.95 & 4,88 & $0.000^{* * *}$ \\
Attention $\times$ Spatial Separation & 0.19 & 2,44 & 0.805 \\
Attention $\times$ Area & 48.00 & 4,88 & $0.000^{* * *}$ \\
Spatial Separation $\times$ Area & 5.01 & 8,176 & $0.000^{* * *}$ \\
Attention $\times$ Spatial Separation $\times$ Area & 1.16 & 8,176 & 0.333 \\
\hline
\end{tabular}

Repeated measures GLM with factors attention (attend vs. unattended), spatial separation $\left(2^{\circ}\right.$ vs. $4^{\circ}$ vs. $\left.7^{\circ}\right)$ and area (V1, V2, VP, V4, TEO). Per subject, three runs were included, except for one subject, where one of the runs had to be discarded due to technical problems. $P$ values are Greenhouse-Geisser corrected whenever more than 1 degree of freedom was present in the numerator.

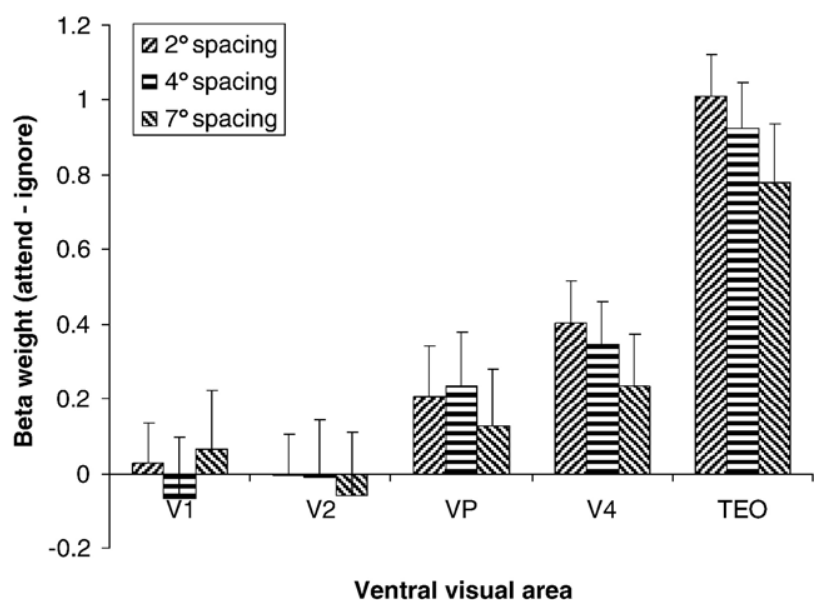

Fig. 4. Results of the region of interest analysis. Displayed are beta weight differences between attended and unattended conditions. Bars indicate the difference between the beta weights estimated for the attended and the unattended conditions averaged across runs, plotted separately for each of the mapped visual areas and for each of the spatial separations. Error bars display standard errors.

decreased in conditions where competitive interactions take place among stimuli. Furthermore, we explicitly tested the more specific prediction of the biased competition theory that the difference between attended and unattended displays should be scaled to an area's RF size at a given eccentricity and the spacing between stimuli.

To investigate this, a direct comparison was made between attended and unattended presentations of stimuli with different spatial separations. BOLD signal changes were analyzed within participant's predefined visual areas of interest (contralateral ventral V1, V2, VP, V4, TEO). Our results support the biased competition model. The observed difference between attended and unattended displays was scaled to RF size of the reported areas; attention effects increased as RF size became larger. Furthermore, the smallest display that led to a difference between attended and unattended displays, matched the estimated size of the RF for that area. In lower order areas like V1 and V2, no attention effect was observed in any of the display spacings. Unexpectedly, we did not observe any significant attention effects in area VP. Possibly, our pictures were displayed at an eccentricity at which RF size was still too small to lead to competitive interactions for our smallest displays. Previously, attention effects have been observed in this area, but with stimuli presented at higher eccentricity (Kastner et al., 2001), where RF sizes are larger. Further up the ventral stream, where RF size increases, attention effects were observed. Area V4 exhibited an attention effect for both $2^{\circ}$ and $4^{\circ}$ displays, confirmed by significant $t$ tests, and no effect for $7^{\circ}$ displays. In addition, the .057 probability in the difference contrast indicated a trend for a larger attention effect for $2^{\circ}$ and $4^{\circ}$ compared to $7^{\circ}$ displays in V4. This result is in agreement with the estimated RF size of neurons in that area of about $4^{\circ}$ for that eccentricity (Boussaoud et al., 1991; Gattass et al., 1988; Smith et al., 2001). Similarly, in TEO all spatial separations led to the predicted attention effect, which is in agreement with the estimated RF size in TEO of 6-7 $7^{\circ}$ (Boussaoud et al., 1991).

These data support the notion that the observed decrease in BOLD signal change in high competition conditions is a consequence of suppressive interactions between stimuli rather 
than a differential amount of transient stimulus onsets. Specifically, the data suggest that higher up the hierarchy of visual areas, competitive interactions between stimuli occur over larger distances, which is in agreement with the idea that these interactions are scaled to RF size. Correspondingly, the effect of attention on stimulus displays where competitive interactions take place also depends on the size of the RF of an area and the size of the stimulus display. The present findings further support the idea that biased competition, which has been studied predominantly with primate single-cell recordings, might also be at work in the human brain as a dominant stimulus selection mechanism.

\section{Acknowledgments}

This project was supported by NWO ASPASIA Grant No. 015.001.053 to B.M. Jansma (Schmitt) and by NWO Grant No. 402-01-632 to R. Goebel.

The authors would like to thank Elia Formisano, Boukje Habets and Alard Roebroeck for valuable discussions in the preparation phase of the manuscript. Furthermore, we would like to thank Henk Jansma for his help on segmenting our subjects' brains and Paul Gaalman for technical assistance during the fMRI measurements.

\section{References}

Boussaoud, D., Desimone, R., Ungerleider, L.G., 1991. Visual topography of area TEO in the macaque. J. Comp. Neurol. 306, 554-575.

Broadbent, D., 1958. Perception and Communication. Pergamon Press, London.

Chelazzi, L., Duncan, J., Miller, E.K., Desimone, R., 1998. Responses of neurons in inferior temporal cortex during memory-guided visual search. J. Neurophysiol. 80, 2918-2940.

Chelazzi, L., Miller, E.K., Duncan, J., Desimone, R., 2001. Responses of neurons in macaque area V4 during memory-guided visual search. Cereb. Cortex 11, 761-772.

Desimone, R., Duncan, J., 1995. Neural mechanisms of selective visual attention. Annu. Rev. Neurosci. 18, 193-222.

Fox, P.T., Raichle, M.E., 1985. Stimulus rate determines regional brain blood flow in striate cortex. Ann. Neurol. 17, 303-305.

Gattass, R., Gross, C.G., Sandell, J.H., 1981. Visual topography of V2 in the macaque. J. Comp. Neurol. 201, 519-539.

Gattass, R., Sousa, A.P., Gross, C.G., 1988. Visuotopic organization and extent of V3 and V4 of the macaque. J. Neurosci. 8, 1831-1845.
Goebel, R., Muckli, L., Kim, D.-S., 2003. The visual system. In: Paxinos, G., Mai, J.K. (Eds.), The Human Nervous System. Academic Press, New York.

Kastner, S., Ungerleider, L., 2001. The neural basis of biased competition in human visual cortex. Neuropsychologia 39, 1263-1276.

Kastner, S., De Weerd, P., Desimone, R., Ungerleider, L., 1998. Mechanisms of directed attention in the human extrastriate cortex as revealed by functional MRI. Science 282, 108-111.

Kastner, S., Pinsk, M.A., De Weerd, P., Desimone, R., Ungerleider, L., 1999. Increased activity in human visual cortex during directed attention in the absence of visual stimulation. Neuron 22, 751-761.

Kastner, S., De Weerd, P., Pinsk, M.A., Elizondo, M.I., Desimone, R., Ungerleider, L., 2001. Modulation of sensory suppression: implications for receptive field sizes in the human visual cortex. J. Neurophysiol. 86, $1398-1411$.

Luck, S.J., Chelazzi, L., Hillyard, S.A., Desimone, R., 1997. Neural mechanisms of spatial selective attention in areas V1, V2, and V4 of macaque visual cortex. J. Neurophysiol. 77, 24-42.

Miller, E.K., Gochin, P.M., Gross, C.G., 1993. Suppression of visual responses of neurons in inferior temporal cortex of the awake macaque by addition of a second stimulus. Brain Res. 616, 25-29.

Moran, J., Desimone, R., 1985. Selective attention gates visual processing in the extrastriate cortex. Science 229, 782-784.

Pinsk, M.A., Kastner, S., Desimone, R., Ungerleider, L., 1999. An estimate of receptive field sizes in human visual cortex. Neurolmage 9, s885.

Price, C.J., Moore, C.J., Frackowiak, R.S., 1996. The effect of varying stimulus rate and duration on brain activity during reading. NeuroImage $3,40-52$.

Recanzone, G.H., Wurtz, R.H., Schwarz, U., 1997. Responses of MT and MST neurons to one and two moving objects in the receptive field. J. Neurophysiol. 78, 2904-2915.

Rees, G., Frackowiak, R., Frith, C., 1997. Two modulatory effects of attention that mediate object categorization in human cortex. Science $275,835-838$.

Reynolds, J.H., Chelazzi, L., Desimone, R., 1999. Competitive mechanisms subserve attention in macaque areas V2 and V4. J. Neurosci. $19,1736-1753$.

Schneider, W., Casey, B.J., Noll, D., 1994. Functional MRI mapping of stimulus rate effects across visual processing stages. Hum. Brain Mapp. $1,117-133$.

Sereno, M.I., Dale, A.M., Reppas, J.B., Kwong, K.K., Belliveau, J.W., Brady, T.J., Rosen, B.R., Tootell, R.B.H., 1995. Borders of multiple visual areas in human revealed by functional magnetic resonance imaging. Science 268, 889-893.

Smith, A.T., Singh, K.D., Williams, A.L., Greenlee, M.W., 2001. Estimating receptive field size from fMRI data in human striate and extrastriate visual cortex. Cereb. Cortex 11, 1182-1190.

Treisman, A.M., 1969. Strategies and models of selective attention. Psychol. Rev. 76, 282-299. 